\title{
2013 Vicência Meteorite Found in Brazil: Preliminary Classification Efforts Based on Traditional Approaches and Cathodoluminescence (CL) Maps.
}

\author{
Amanda Tosi ${ }^{1}$, Breno Leite ${ }^{2}$, Isabel. P. Ludka ${ }^{1}$ and Maria E. Zucolotto ${ }^{3}$ \\ 1. Universidade Federal do Rio de Janeiro, Departamento de Geologia, Rio de Janeiro, Brazil. \\ 2. JEOL USA Inc, Peabody, United States. \\ 3. Museu Nacional \& Universidade Federal do Rio de Janeiro, Rio de Janeiro, Brazil. \\ (mezucolotto@globo.com)
}

A meteorite fall took place on September 21, 2013 in a tiny village called Vicência (also known as Vila da Borracha), located at Brazil's northeast region, more specifically on the northwest of Pernambuco State. The meteorite almost struck a man (Mr. Adeildo) who noticed that one of the rock sides was still warm. The meteorite is now at the Rio de Janeiro National Museum for petrological classification. In this paper we describe the study of cathodoluminescence (CL) emission after exposing thin specimen of the meteorite slices to an electron beam, as an aid to traditional classification methods.

The Vicência meteorite was recognized as a chondrite. Chondrites are the most primitive known rocks of the Solar System. It contains chondrules, roughly spherical aggregates of silicate minerals not found on terrestrial rocks. The study of chondrules brings insights into the processes that occurred in the Solar Nebula, at the most primitive moments in the Solar System history. Since their formation, the meteorites were altered, by thermal metamorphism or aqueous alteration so much that a classification scheme of chondrites was created by Van Schmus and Wood [1]. Obviously the "petrological types" (3 to 6) are based on the amount of metamorphism detected. Sears et al [2] subdivided type 3 into finer divisions ranging from 3.0 to 3.9 , covering full variation in their metamorphic properties. Vicência is among the primitive un-equilibrated ordinary chondrites; exhibiting outstanding defined chondrules within a gray matrix (Fig. 1). Notably, it is a very rare type of chondrite and interesting to science because it nearly skipped metamorphism on its parent body. Falls of such primitive chondrite are very rare.

In our efforts to confirm early assessments, a thin petrographic slide preparation was examined using an Electron Probe Microanalizer (JEOL EPMA-JXA-8230). The cathodoluminescence signal from a typical representative area of the Vicência meteorite was collected using a red, a blue and a yellow filter. The wavelength of emitted light reflects the chemical composition and crystallographic structure of the analyzed specimen. Subsequently, the generated images (red, blue and yellow) were merged to form a single image. CL maps are known to reveal, for instance, the presence of $\mathrm{Fe}^{2+}$ known to reduce the luminescence, the presence of calcium intensifies yellows and reds, contrasting with blue feldspars [3]. The presence of activators (increasers) and quenchers (reducers) of CL expose the summation of the chemical character of a meteorite. This capability was quickly envisioned as a rich systematic tool. Cathodoluminescence is currently used in geological classification. In this work we are using a Cathodoluminescence imaging method of meteorite grouping developed by Meier and collaborators [3]. The CL of Vicência exhibits a range of color intensities of yellow CL associated to the chondrule mesostasis slightly higher than the red CL and few grains with blue CL corresponding to the lowest levels of metamorphism (Fig. 2). The CL images of the Vicência meteorite indicate that it is closely related to Bishunpur (L3.1) thus classifying it as very primitive (3.1, Sears system) [4,5]. We will continue the work to further refine and confirm our findings. 
References:

[1] V. Schmus, W. R.; Wood, J. A. (1967). Geochimica et Cosmochimica Acta 31 (5): 747-765.

[2] D.W.G. Sears et al (1980) Nature 287: 791-795

[3] Meier et al (2003). Lunar and Planetary Science XXXIV.

[4] D.W.G. Sears et al Chemie de Erde (2013) 73:1-37.

[5] D.G. Akridge et al (2004). J. of Geophysical Research 109: E07S03

Authors acknowledge Dr. Natasha Erdman (JEOL USA Inc.) for critically reviewing the manuscript, Mr. André Moutinho, meteorite collector, and FAPERJ for a supporting grant.

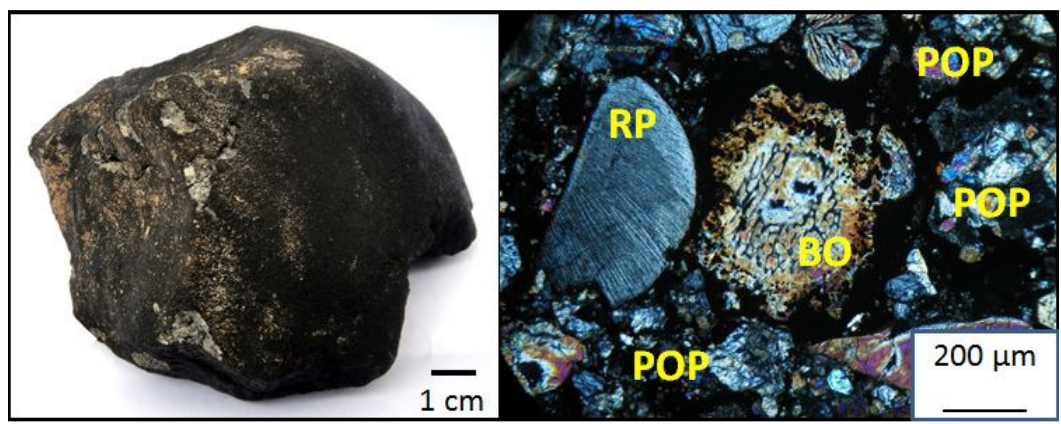

Figure 1. Vicência meteorite (left). Thin section of Vicência under cross-polarized light showing a barred olivine (BO) chondrule made of short barred olivines with an internal rim of the same material and an external rim rich in metal and sulfides. The BO chondrule is surrounded by a dark matrix and is in the vicinity of at a radial pyroxene's half (RP), In addition, we can notice chondrules and their fragments of porphyritic olivine pyroxene (POP), as a consequence of the size diversity and fractured olivine crystals collection (right).

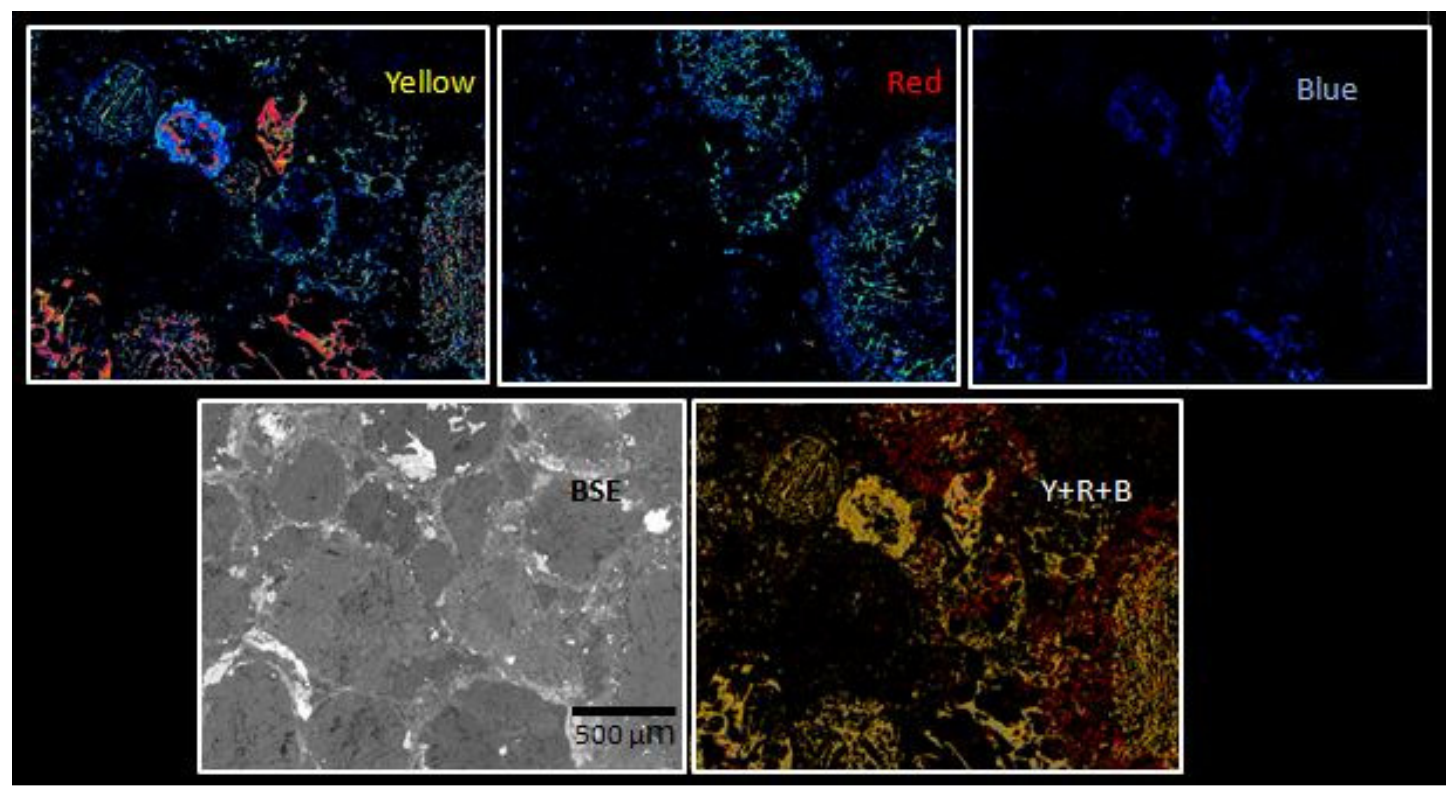

Figure 2. Individual CL maps of a thin section of meteorite taken using JEOL - JXA-8230 (upper images); corresponding backscattered electron image (bottom left); merged images of Red, Blue and Yellow CL maps (bottom right). 